\title{
Trade-off Analysis between the Indexes of Cultivated Land Health Evaluation
}

\author{
Mei Shan ${ }^{1, a}$ and Xun Wang ${ }^{2}$ \\ ${ }^{1}$ School of Tourism, Taishan University, Tai'an, Shandong 271000, China \\ ${ }^{2}$ Tai'an Environmental Protection Bureau, Tai'an, Shandong 271000, China
}

\begin{abstract}
Cultivated land is the basis for the survival and development of human society. The selective utilization of human factors and the level of utilization are the decisive factors to promote the external performance of cultivated land. The quality components of cultivated land in different regions have their own characteristics, and the external performance is different. This paper analyzed the China southern city of major grain producing areas of cultivated land within the health influence of constituent elements and characteristics of the relationship between each other, there are dominant factors to find the current utilization level under the influence of the external manifestations of the health of cultivated land, but also conducive to the area of cultivated land ecological function of human selective use, finally get maximum benefit of land use, the best function cultivated land.
\end{abstract}

\section{Introduction}

Cultivated Land is the essential material foundation for the agricultural production and the most basic living condition for the human beings ${ }^{[1]}$.

Cultivated health is the ecological system to be able to maintain a dynamic balance. It is not affected by cultivated land fertility, between life and the environment in a certain region of soil pollution, land structure, land use change, land resource constraints, the formation of an energy flow and material circulation dynamic system. Healthy cultivated land has rich fertility, no pollution, land structure is reasonable, land use change is small and land resources are abundant ${ }^{[2],[3],[4]}$.

The external performance of cultivated land health is the productivity of arable land and the environmental health and safety of cultivated land ${ }^{[5]}$.

The study selected cultivated land productivity and soil environmental indicators two indicators for cultivated land health assessment ${ }^{[6-8]}$. In order to provide the basis for rational utilization of healthy cultivated land and the maximum ecological function of healthy cultivated land in the region, the determinant factors affecting the health of cultivated land are found through the analysis of the relationship between the individual characteristics and the components of the components of cultivated land health in the main grain producing areas of southern China.

In order to ensure and maintain the health of cultivated land, it is necessary to balance the quality of cultivated land, increase the productivity of cultivated land and decrease the soil environment of cultivated land, and not reduce the soil environmental quality of cultivated land on the premise of guaranteeing the quality of cultivated land and the productivity of cultivated land.

\section{Correlation analysis of quality components of cultivated land}

When evaluating the quality of cultivated land in the study area, the main factors were selected as indicators: $\mathrm{PH}$ value, soil surface texture, soil organic matter content, effective soil layer thickness, cultivated land cover assurance rate, cultivated land barrier depth, soil salinization degree and drainage condition, etc ${ }^{[9]}$.

The range of cultivated land quality in the final evaluation unit is 67.44 90.41, which is divided into 10 cultivated land quality with 5 points as equal spacing, among which the quality of cultivated land in the study area is $6-10$

In the evaluation of soil environment of cultivated land, the heavy metal elements of soil heavy metal elements, such as arsenic, cadmium, chromium, copper, mercury, lead, zinc and nutrient element selenium, were selected as evaluation indexes. According to the standard of soil environmental quality (GB15618-2008), the content of heavy metals in the cultivated soil in the study area was not exceeding the standard. The weight of heavy metals in soil environment was determined by analytic hierarchy process (AHP). The range of cultivated land environment index in the evaluation unit was $0.31-0.79$, and 0.1 was divided into equal space. The soil environment in the study area was 4-8.

The three indexes of cultivated land in the study area, such as the quality of cultivated land, the productivity of

$\overline{{ }^{\mathrm{a}} \text { Corresponding author: tigertaishan } @ 163 . c o m}$ 
cultivated land and the soil environment of cultivated land, etc., such as Figure 1, figure 2, and figure 3, are shown in Table 1 of the area ratio of each other arable land.

Table 1. Statistical table of cultivated land area ratio in a city in southern China

\begin{tabular}{|c|l|l|l|l|l|l|l|l|l|l|l|}
\hline \multicolumn{1}{|c|}{ grade } & 1 & 2 & 3 & 4 & 5 & 6 & 7 & 8 & 9 & 10 & 合计 \\
\hline Capacity grade $(\%)$ & 1.18 & 6.67 & 3.67 & 9.02 & 17.66 & 15.36 & 31.89 & 7.52 & 5.02 & 2.01 & 100 \\
\hline Unit ammber & 1300 & 4719 & 2138 & 6072 & 18410 & 19091 & 36739 & 7635 & 4448 & 1072 & 101624 \\
\hline $\begin{array}{l}\text { Soll environmental } \\
\text { grade (\%) }\end{array}$ & - & - & - & 12.10 & 38.37 & 25.45 & 16.02 & $8.06 \%$ & - & - & 100 \\
\hline Unitumber & - & - & - & 17637 & 39649 & 22348 & 14320 & 7670 & - & - & 101624 \\
\hline
\end{tabular}

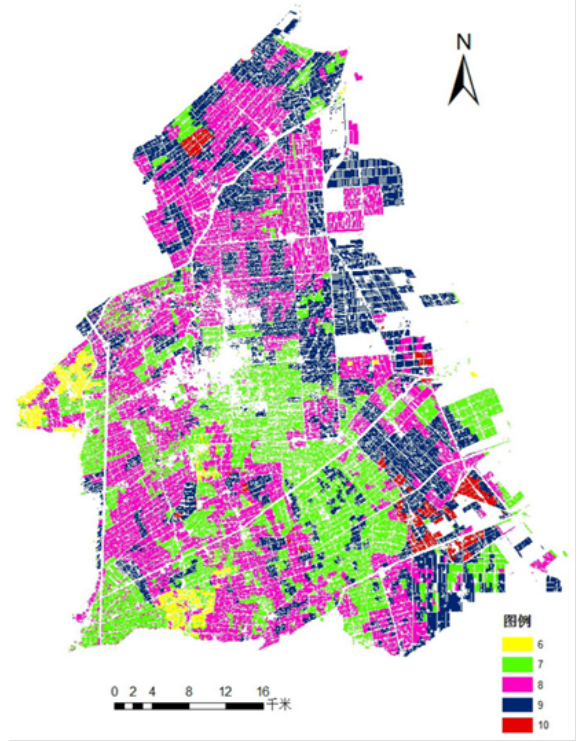

Figure 1. A city in southern China quality of cultivated land distribution map

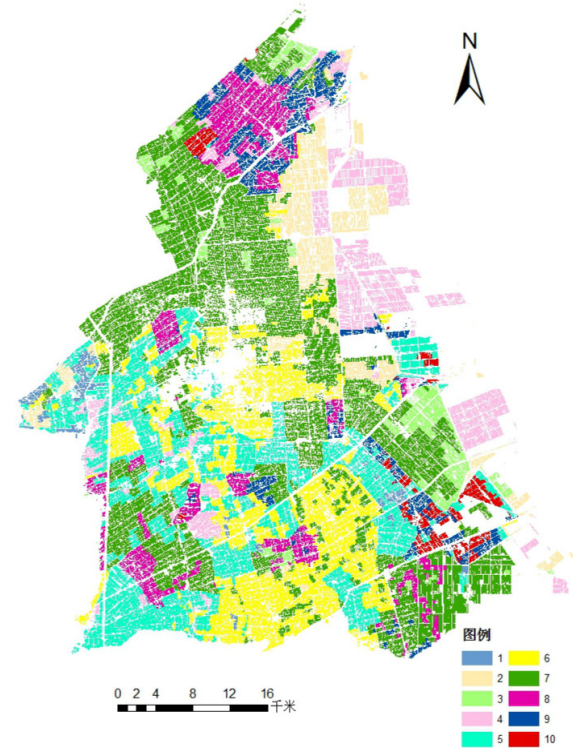

Figure 2. A city in southern China land productivity distribution map

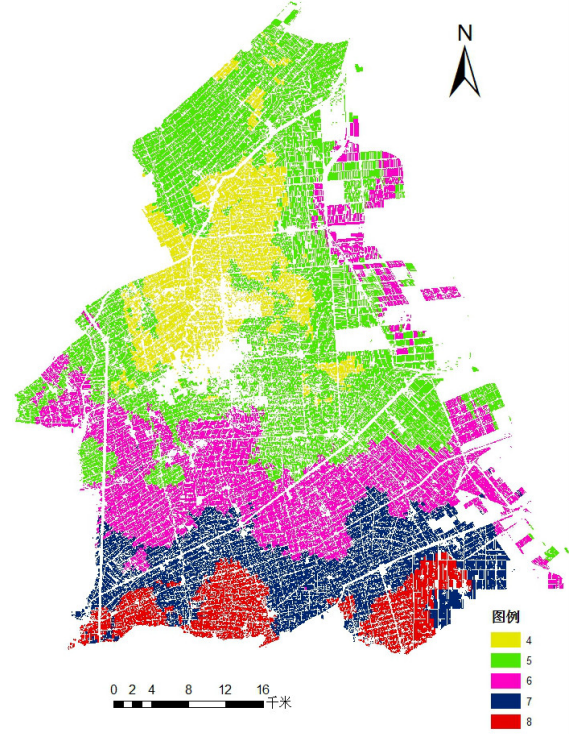

Figure 3. A city in southern China distribution of cultivated soil environment

From Figure 5.1 and Figure 5.2, we can see that different from the grade distribution of cultivated land, the soil environment grade of cultivated land decreases gradually from the south to North grade in the study area, of which the content of heavy metals in the southern region is the least, and the northwest is the highest. According to table 5.1, the quality grade of cultivated land in the study area is 6 and 10 , only about $3 \%$, only about $3 \%$, and the other grades are evenly distributed; the productivity grade of cultivated land is only $5,6,7$ and so on, and the distribution of the other grades in the study area is less; the soil environment grade of cultivated land is mainly 4-7. The three indexes of cultivated land health were calculated by the grade area weighted method. The average cultivated land quality grade of the study area was 8.03 , the average cultivated land capacity grade was 7.13 , and the soil environment grade of the average cultivated land was 5.70 .

\subsection{Correlation analysis between cultivated land quality grade and cultivated land productivity grade}

The corresponding relationship between cultivated land productivity and weighted average arable land quality grade is obtained by area weighted method, as shown in Figure 4.

Figure 4 shows that when the productivity level is 10 , the average arable land quality level is the highest, and the average arable land quality level is the lowest when the productivity level is 1 . Although the lowest and highest level of cultivated land capacity level is not necessarily the worst and the best, as a whole, figure 5.4 shows that with the increase of the productivity grade of cultivated land, the corresponding average quality of cultivated land also gradually increase, indicating that the two is a positive correlation trend. 


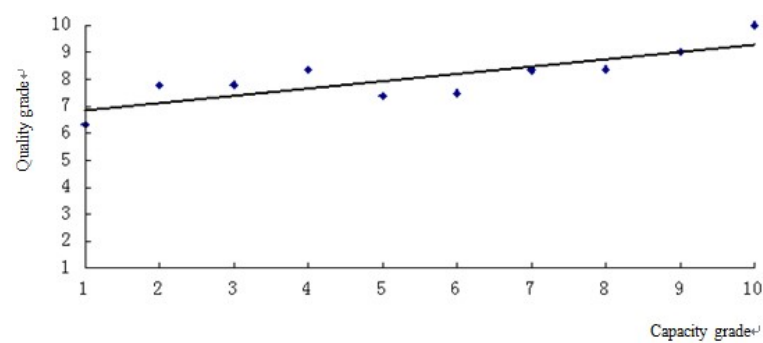

Figure 4. Farming estate relationship with the corresponding average cultivated land quality map

The total area of cultivated land with a production level of 10 is very small, accounting for only $2.01 \%$ of the total area of the study area. This area belongs to the coastal low-lying area, the East is the tidal flat wetland, the soil is more fertile, it is a centralized farming area, the agricultural irrigation and drainage infrastructure is relatively complete. The soil quality in the area is excellent because of the cumulative effect of cultivated land use. In addition, fine farming has high productivity.

The arable land with capacity level of 4 is mainly distributed in the eastern coastal area of the study area, and the content of chloride salt is relatively high due to seawater immersion for many years. Most of the new reclamation area is heavy saline soil. The old reclamation area is mostly middle saline soil and light saline soil, and a few of them are desalting soil. High salinity inhibits the growth of crops. The drainage and drainage system has been developed by means of improving the salting soil such as river drainage, fresh water washing and planting green manure. With the effect of salinization, the quality of cultivated land is relatively low, but the productivity of cultivated land is relatively low.

The quality of cultivated land in the area where the productivity grade is 1 is poor, and the industrial enterprises of these towns are more developed. Because of the reason of land use, the agricultural input is low, which leads to the low productivity of cultivated land.

According to the above analysis, the quality of cultivated land in the study area is a key factor affecting the productivity of cultivated land. At the same time, the income of cultivated land, the convenience of farming, and the conditions of cultivated land infrastructure determine the development and utilization of the healthy cultivated land.

At present, part of the cultivated land in the region has not fully played the role of the quality of cultivated land, and the capacity of cultivated land still has room for improvement.

\subsection{Correlation analysis between cultivated land environmental classification and cultivated land productivity grade}

The corresponding relationship between cultivated land environment and the weighted average cultivated land productivity level is shown in Figure 5.

Figure 5 shows that the overall average soil environmental quality level decreases slowly with the increase of cultivated land energy level, and the two has a negative correlation, which indicates that human utilization in the study area has a certain negative impact on the soil environmental health of cultivated land. In addition to the grade 5 and 6 grade, the average soil environmental quality grade corresponding to the quality grade of cultivated land is lower than that of the average cultivated land soil environmental quality grade 5.70 in the region, which indicates that the actual production capacity of cultivated land in the study area is not obviously affected by the soil environmental quality condition.

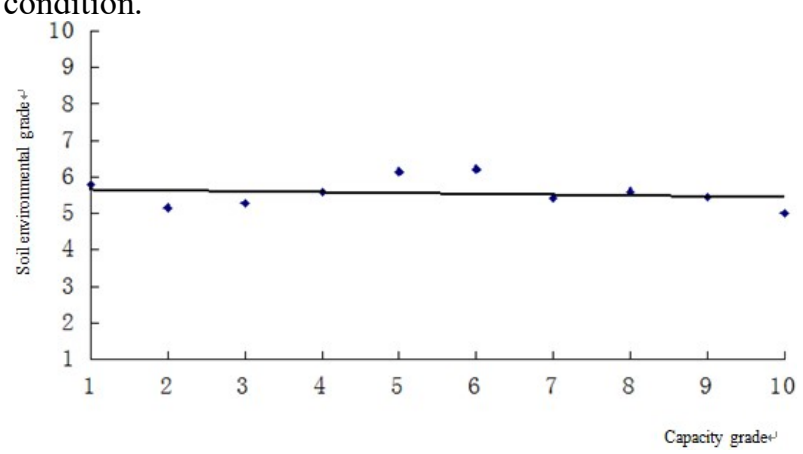

Figure 5. Land environment and the corresponding average cultivated land capacity diagram

The grade 5 and 6 of cultivated land are mainly distributed in the middle and south areas of the study area. Because of the protection of the environment in the area, the agricultural industrial structure is adjusted and the ecological agriculture is vigorously developed, so the cultivated land soil environment is also improved while improving the productivity of the cultivated land.

The area with the lowest productivity grade (1) is mainly located in the Midwest of the research area, which has obvious advantages in the industrial field, in which the six industries, such as textile, machinery, light industry, chemical, building materials and toys, have formed a scale. Because of the low input of direct agricultural input in the region, the actual production of cultivated land is low, but the corresponding soil environmental quality is poor, especially the region of low lying land is the irrigation and irrigation area of the farming area.

The area with the highest productivity grade of cultivated land, due to the more chemical substances such as chemical fertilizers and pesticides in the process of agricultural cultivation, and the greater influence of human production and life, so the productivity of the cultivated land is high, but the soil environment health condition is relatively poor because of the influence of chemical fertilizer and pesticide.

Through the above analysis, we can see that the current soil environmental quality in the study area is not the main restriction factor for the realization of the regional cultivated land health, and the regional cultivated land can bring some negative effects on the soil environmental health, but it does not change its main characteristics. The change trend of soil environmental quality of cultivated land reflects the result that the irrational utilization of human will bring about the deterioration of the quality of soil environment. In the use of cultivated land, we should pay attention to the 
enrichment of chemical fertilizer and pesticide in the process of agricultural cultivation.

\subsection{Correlation analysis between cultivated land quality grade and cultivated land soil environmental grade}

The correspondence between soil environmental quality and weighted average cultivated land quality in a city is shown in Figure 6.

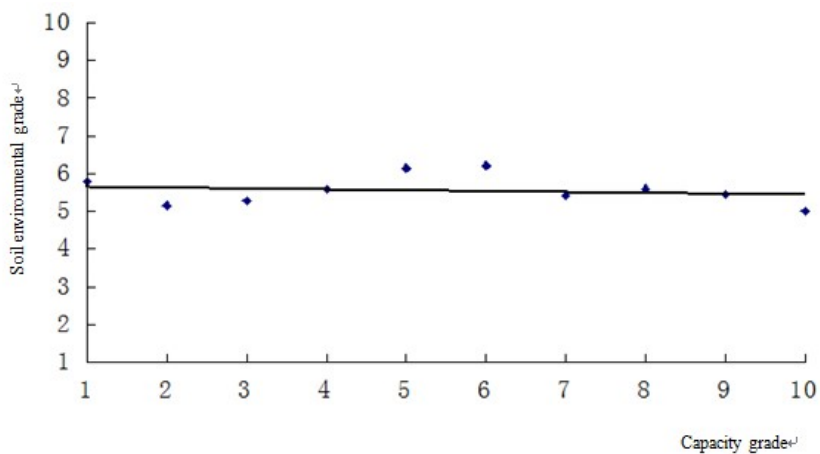

Figure 6. Quality of cultivated land and the corresponding average soil environment diagram

Figure 6 shows that, on the whole, with the increase of cultivated land quality grade, the corresponding average soil environmental grade has slowly decreased, indicating that the two have a negative correlation. 10 of the best cultivated land in the study area is located in the southeast of the study area. The irrigation and drainage conditions of cultivated soil are better, and the organic quality is high. The ability of soil to adsorb heavy metals such as $\mathrm{As}$ and $\mathrm{Cd}$ increases with the increase of $\mathrm{pH}$, and increases with the increase of organic matter content ${ }^{[10-11]}$.

The $\mathrm{pH}$ value in the study area is $7.5-8.5$ and the organic matter content is $0.91 \%-1.77 \%$. In the background of higher soil $\mathrm{pH}$ value and higher soil organic matter content in the study area, the $\mathrm{pH}$ value and organic content of some cultivated soil are relatively low, and the content of heavy metals adsorbed in this part is relatively small, so the quality of cultivated land is relatively poor and the quality of soil environment is relatively good. On the contrary, with the improvement of cultivated land quality, the amount of chemical fertilizer and pesticide application will increase correspondingly, which will eventually lead to the decline of soil environmental quality.

\section{Balance of health evaluation index of cultivated land}

Soil provides nutrients and moisture for crops to grow That is to say, the high quality of cultivated land can achieve high productivity and maintain the survival and reproduction of human beings. However, things have two sides. On the one hand, if there is no sufficient nourishment and water, that is, the soil is not "fertile", the crops can not grow normally, not to get a stable yield or high productivity. On the other hand, the nutrient content in the soil is often provided for the growth process of the crops. It needs to be unbalanced, so it needs to be adjusted in the growth cycle of the crops. In the process of farming, human beings, intentionally or unintentionally, add various "harmful" elements which are not conducive to the growth of the crops, so that the soil and the surrounding water are polluted in different degrees, and the quality of the soil environment is reduced, and the farmers are eventually led to the agriculture. The deterioration of product quality affects the health of human body. The results show that there are correlations between three indicators of cultivated land health in the study area. To protect the health of cultivated land, we must weigh the quality of cultivated land, the capacity of cultivated land and the soil environment of cultivated land.

The quality of cultivated land in the study area has a positive correlation with the productivity of cultivated land, which indicates that the cultivated land productivity increases with the increase of cultivated land quality, and the quality of cultivated land has a negative correlation with the soil environment of cultivated land, which indicates that the research area has a negative effect on the quality of cultivated land and the environment of the cultivated land. It has a negative correlation with the soil environment of cultivated land, which shows that the increase of soil fertility by the way of improving the soil fertility has also increased the yield per unit area of crops, but also has a negative impact on the soil environment. Because the research area is located in the coastal plain area, it is the country's top 100 county economy, the level of industrialization and urbanization is high, and the economic conditions are superior, so the productivity of cultivated land has great potential for promotion. In addition, the research area government attaches great importance to environmental protection work, strengthens the management of pollutant discharge enterprises and reduces the source of soil pollution in cultivated land, so the soil environment has not been greatly impacted. Although the heavy metal content of soil in the cultivated land has not exceeded the standard at present, the soil environment of cultivated land is still clean, but the change trend of soil environmental quality and so on with the increase of cultivated land productivity and the quality of cultivated land has been warned, which reminds us that the cultivated land should be paid attention to the cultivated land and the cultivated land should be paid attention to. The rational utilization can avoid the deterioration of soil environmental quality of arable land.

\section{Conclusion and discussion}

This paper provides an example for the study of the theory of cultivated land health evaluation through the study of the relationship between the productivity of cultivated land and the soil environmental quality of the cultivated land. It can be more intuitively found out the size of the function of the various components of cultivated land and the pressure under the current 
cultivated land use intensity, and the cultivated land is in the field of cultivated land. As an evaluation unit, block can be directly used to guide people to take appropriate use and moderate utilization of cultivated land, and provide a theoretical basis for the sustainable utilization of healthy cultivated land.

\section{Acknowledgements}

This work was supported by the scientific research project of taishan university (No: Y-01-2017002)

\section{References}

1. Zeqiang Fu, Yunlong Cai. Correlation analysis between China's food security and the change of cultivated land resources [J]. Journal of natural resources, 2001, 16(4): 313-319

2. Qiang Li, Jinming Yan, Ye Zhao. The health of farmland also needs to diagnose [J]. China land, 2011(11): 37-39

3. CALLICOTT J B, FREYFOGLE E T. Aldo Leopold for the Health of the Land(Previously Unpublished Essays and Other Writings)[M]. Washington: Island Press, 1999.1-3
4. DORAN J W, PARKIN T B. Soil health and sustainability[J]. Advances in Agronomy, 1996, 56: 2-55

5. zhaoyou Liu, Xin Ma, Mao Xu. Early warning of cultivated land quality [J]. China land science, 2003, 17(6): 9-12

6. Pank Hurst C E Hawke B G Mcdonald H J et al. Evaluation of soil biological properties as potential bioindicators of soil health J Australian Journal of Experimental Agriculture, 1995, 35, 1015-1028

7. Qiguo Zhao, Bo Sun, Taolin Zhang. Soil quality and sustainable environment [J]. soil, 1997, (3): $113-120$

8. Tianjie Li, Keli Zhang, et al. Soil geography (Third Edition) [M]. Beijing: Higher Education Press, 2004: 286-300

9. Ochola WO, Kerkides P. An integrated indicatorbased spatial decision support System of land quality assessment in Kenya. Computers and Electronics in Agriculture, 2004.45:3-26

10. ROSS S M Toxic Metals in Soil-plant Systems [M. New York: John Wiley \& Sons Ltd, 1994

11. S. Kalogirou. (2002). Expert Systems and GIS: an application of land suitability evaluation. Computers. Environment and Urban Systems, 26, 89-112 